REPORTE DE CASOS

\title{
Aborto por Leptospira en una yegua en Salta, Argentina
}

\author{
Micheloud $\mathrm{JF}^{1^{*}}$, Martínez $\mathrm{M}^{3}$, Zurita $\mathrm{SG}^{2}$, Grune $\mathrm{S}^{3}$, Romero $\mathrm{G}^{3}$, Brihuega $\mathrm{B}^{3}$ \\ 1 Grupo de Trabajo de Patología, Epidemiología e Investigación Diagnóstica. Área de Sanidad Animal-IIACS Salta, \\ Instituto Nacional del Tecnología Agropecuaria (INTA), Salta, Argentina \\ 2 Facultad de Ciencias Agrarias y Veterinarias, Universidad Católica de Salta \\ 3 Laboratorio de Leptospirosis- Instituto de Patobiología. INTA-Castelar \\ * Correspondencia: JF Micheloud. Grupo de Trabajo de Patología, Epidemiología e Investigación Diagnóstica. Área de \\ Sanidad Animal-IIACS Salta/INTA. RN 68, km 72- Salta, Argentina. \\ E-mail: micheloud.juan@correo.inta.gob.ar
}

Recibido: 23 Febrero 2016. Aceptado: 23 Abril 2016. Disponible en línea: 26 Abril 2016

Editor: R. Sobrero

RESUMEN. La leptospirosis en equinos es generalmente asintomática, aunque existen regiones donde la enfermedad constituye un problema. Aquí se describe un caso de aborto en yegua debido a la infección por este agente. Se efectuó la necropsia completa de un feto a término donde se colectaron muestras para inmunofluorescencia directa (IFD), histopatología y microbiología. Además, se efectuó un estudio serológico de la tropilla y se evaluó seroconversión en la yegua abortada. El feto evidenció hepatomegalia, esplenomegalia e ictericia. Microscópicamente se apreció hepatitis mononuclear con disociación de los hepatocitos, esplenitis aguda y glomérulo-nefritis. Aunque el microrganismo no pudo ser aislado, la enfermedad se confirmó por la seroconversión observada en la yegua abortada, y debido a la identificación del agente mediante IFD en la impronta renal. Este caso demuestra la presencia del agente localmente y evidencia que la enfermedad puede ser un problema para la producción ecuestre.

SUMMARY. Abortion caused by Leptospira in a mare from Salta Province, Argentina. Leptospirosis in horses is usually asymptomatic, although there are regions where the disease is a problem. Here, a case of abortion caused by the agent in a mare is described. Full autopsy of a fetus at term was performed; samples for direct immunofluorescence (DIF), histopathology and microbiology were collected. Additionally, a serological study of the herd was conducted, as well as seroconversion in the aborted mare. The fetus evidenced hepatomegaly, splenomegaly and jaundice. Microscopically, mononuclear hepatitis with hepatocyte dissociation, acute splenitis and glomerulonephritis, were appreciated. Although the microorganism couldn't be quite properly, the disease was confirmed by the seroconversion present in the aborted mare. Another factor was the identification of the agent through the renal imprint DIF. This case demonstrates the presence of the agent mentioned locally, and evidences that the disease can represent a problem to the equestrian industry.

Palabras clave: leptospirosis; pérdidas reproductivas; aborto equino.

Key words: leptospirosis; reproductive loss; equine abortion.

La leptospirosis es una enfermedad infecciosa producida por bacterias del género Leptospira, capaz de afectar a los animales y al hombre (Stanchi et al., 2007). La susceptibilidad de los equinos fue demostrada por Nieschulz y Wawo-Roentoe en 1930 (Wegmann, 1983) y es particularmente común en algunas regiones del mundo (Verma et al., 2013). Por muchos años se pensó que esta especie no constituía un reservorio para ningún serovar de Leptospira y estudios serológicos en varios países indicaban que las infecciones en equinos provenían de otros reservorios (Verna et al., 1977; Carpio et al., 1979). En caballos el cuadro clínico por lo general es de carácter leve o subclínico, pueden producirse abortos o mortalidad perinatal, trastornos respiratorios y cuadros de uveítis recurrente o iridociclitis (Verma et al., 2013). Aquí se describe el caso de aborto en una yegua, pertene- ciente a una tropilla de cinco hembras preñadas, de raza Polo Argentino, que se encontraba en un establecimiento ecuestre dedicado a la cría de caballos deportivos, ubicado en la localidad de La Merced, Provincia de Salta, Argentina. Se procedió a efectuar la necropsia completa del feto, se colectaron muestras de tejidos en recipientes estériles y humor acuoso para bacteriología, como así también en formol bufferado al $10 \%$ para histopatología. Se efectuaron improntas de bazo, hígado, riñón y pulmón para la técnica de inmunoflorescencia directa (IFD). Los órganos fueron sembrados en los medios especiales para Leptospira, EMJH y Fletcher y observados semanalmente bajo microscopía de campo oscuro. Se obtuvieron 2 muestras de suero de la yegua abortada (el primer muestreo fue efectuado el día del aborto y el segundo a los 15 días de este). Simultáneamente con el según- 
do muestreo de la yegua, se colectó sangre de cada una de las demás hembras de la tropilla. Los sueros fueron analizados mediante la técnica de microaglutinación (MAT) frente a 8 serovariedades referenciales, Leptospira interrogans serovar Pomona, $L$. interrogans serovar Icterohaemorrhagiae, L. borgpetersenii serovar Castellonis, L. borgpetersenii serovar Tarassovi, L. interrogans serovar Wolfii, L. interrogans serovar Hardjo, L. interrogans serovar Canicola, $L$. kirshneri serovar Grippotyphosa. La dilución inicial del suero fue $1 / 100$. Según los datos recabados en la anamnesis, la yegua no presentó sinología clínica previa al aborto. El feto se encontraba a término (320 días de edad aproximadamente) y a la necropsia se observó ictericia generalizada (Figura 1) con hemorragias petequiales y equimóticas, hepatomegalia y esplenomegalia.

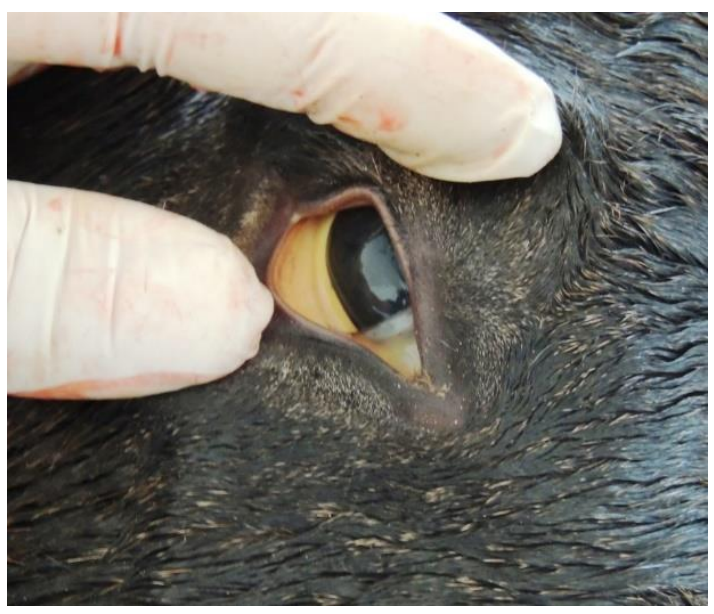

Figura 1. Ictericia de la mucosa ocular en un feto de 320 días de gestación con un diagnostico presuntivo de leptospirosis.

Microscópicamente se evidenciaron hepatitis linfocítica, disociación de los hepatocitos con marcado desorden de los mismos y pérdida del patrón trabecular, con degeneración vacuolar celular y necrosis de las células de Kupffer. A nivel renal se observaron pequeños focos periglomerulares de células mononucleares con degeneración de las células tubulares. A nivel pulmonar se evidenció congestión, atelectasia, áreas de neumonía intersticial y hemorragias focales subpleurales e interlobulares. Los cultivos de riñón en medio EMJH y Fletcher resultaron negativos. La impronta de riñón resultó positiva a la técnica de IFD pero el suero fetal no evidenció títulos a MAT. En el primer muestreo la yegua presentó título de 1/100 para L. borgepetersenii serovar Castellonis del serogrupo Ballum, y en el segundo se evidenciaron títulos de $1 / 800$ para L. borgepetersenii serovar Castellonis, $1 / 800$ para $L$. interrogans serovar Grippotyphosa y $1 / 1600$ para $L$. interrogans serovar Pomona. De las cuatro yeguas restantes, 3 presentaron títulos al serovar Castellonis del serogrupo Ballum (1/400) y una de ellas además presentó títulos para el serovar Grippo- typhosa (1/400) y serovar Pomona (1/600). Finalmente, la cuarta yegua que había sido incorporada recientemente a la tropilla no presentó título a ninguna de las serovariedades evaluadas al momento del muestreo.

La infección por Leptospira spp. ha sido demostrada en equinos en casos de aborto, mortalidad perinatal y muertes neonatales en caballos (Wilkie et al., 1988; Hodgin et al., 1989). Pese a esto por lo general la enfermedad cursa de manera leve y pasa desapercibida (Verma et al., 2013). En este caso se arribó al diagnóstico contemplando las lesiones macro y microscópicas, el resultado de la IFD en la impronta renal y la seroconversión de la yegua que abortó. Desafortunadamente el diagnóstico definitivo suele ser complejo debido a que el aislamiento del microorganismo es difícil por la labilidad que este tiene en el medio ambiente, los largos periodos de incubación que requiere y la baja viabilidad de la bacteria en los tejidos refrigerados (Ellis et al., 1983; Stanchi et al., 2007). Todas estas razones pueden justificar el resultado negativo del aislamiento microbiológico. En este caso la seroconversión observada en el animal permite presumir que el aborto se debió a la infección del serovar Castellonis perteneciente al serogrupo Ballum. La seropositividad a este serogrupo, en casi toda la tropilla, indica que hubo exposición generalizada al agente. Solo una yegua que había sido incorporada una semana antes del muestreo, resultó negativa a MAT, lo que pudo deberse a la falta de exposición al agente o al tiempo insuficiente para que se eleven los títulos de anticuerpos en sangre. La seropositividad a los serovares Grippotyphosa y Pomona pudo tener origen en fenómenos de co-aglutinación. Pese a esto, algunos autores indican que los test serológicos en yeguas tienen un valor relativo debido a que muchos animales presentan títulos a más de una serovariedad de Leptospira (Slatter y Hawkins, 1982; Ellis et al., 1983). La serología resultó negativa en el suero fetal, lo cual ha sido mencionado por otros autores (Poonacha et al., 1993). No se observó ningún aborto en las demás yeguas de la tropilla debido tal vez a que todos los animales fueron tratados con estreptomicina durante tres días inmediatamente de sospechada la enfermedad. Pinna et al. (2012) logró reducir las pérdidas reproductivas en yeguas empleando tratamientos con dihidroestreptomicina y la vacunación correspondiente. Sin embargo, aunque este antibiótico es altamente empleado en el tratamiento de la leptospirosis, su eficacia para eliminar el estado de portador en otras especies ha sido cuestionado (Edwards y Levett, 2004).

Las lesiones macroscópicas encontradas concuerdan con lo mencionado por otros autores (Wilkie et al., 1988; Hodgin et al., 1989; Donahue et al., 1991). La hepatitis mononuclear que se acompaña con un profuso desorden de los hepatocitos que abandonan su formación trabecular típica para distribuirse en agregados o sueltos en el tejido (Figura 2) coincide con lo 
mencionado por Poonacha et al. (1993), Hodgin et al. (1989) que denominan a la lesión como "disociación de hepatocitos".

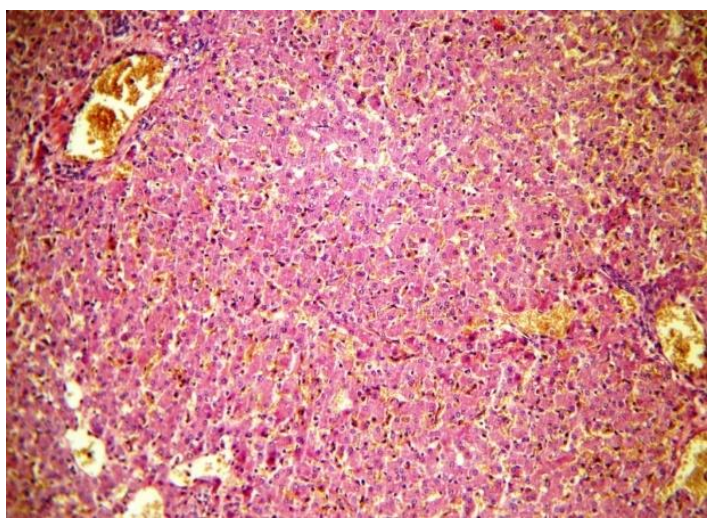

Figura 2. Lesión histopatológica. Disociación de hepatocitos, caracterizada por profuso desorden de las células hepáticas que abandonan su distribución trabecular típico. (H \& E $10 \mathrm{X}$ ).

Estos mismos autores indican que en algunos casos pueden observarse células gigantes (Wilkie et al., 1988; Poonacha et al., 1993). La inmunflorescencia directa es ampliamente usada como método para la demostración de Leptospiras en las muestras de tejidos (Verma et al., 2013) y fue de gran utilidad diagnóstica en este caso ya que permitió evidenciar la presencia del agente en la impronta renal. Esta técnica también ha demostrado ser un método útil para el diagnóstico de leptospirosis en tejidos incluidos en parafina (D'Andrea et al., 2012). Whitwell et al. (2009), empleó la técnica de inmunohistoquímica para la demostración de Leptospiras en los tejidos con cierto éxito, aunque la carga bacteriana debe ser significativa para poder llegar a su identificación. Adler y de la Peña Moctezuma (2010) mencionan que, aunque las técnicas gold-standard son la MAT y el aislamiento mediante cultivo, el empleo de PCR puede permitir un diagnós-tico definitivo y rápido. Por otro lado, Brown et al. (2003) evaluó las técnicas de inmunofluorescencia, cultivo y PCR para el diagnóstico de leptospirosis en muestras post-morten de pacientes humanos; demostrando la baja eficiencia de cualquiera de las técnicas para detectar leptospiras en los tejidos.

Los equinos como cualquier otra especie se infectan a partir de entrar en contacto con animales infectados o a través de la orina $\mathrm{u}$ otros fluidos de animales infectados (Verma et al., 2013). En este caso el brote ocurrió uno a dos meses después de la incorporación de un potro a la tropilla. Aunque no se pudo tener acceso al mismo, el propietario mencionó que animal presentaba lesiones oculares crónicas recidivantes compatibles con un cuadro de uveítis recurrente que pudo haber estado asociado a la infección por leptospira. Pese a que no podemos concluir que esto así sea, es posible que este haya sido la fuente de infección para la tropilla, aunque varios autores ponen en duda el papel del equino como trasmisor de la enfermedad ya que el periodo de leptospiruria es bastante corto (Bryans, 1955; Morter et al., 1969)

Aunque parece ser que en el mundo la presentación clínica de la enfermedad en equinos es infrecuente, la confirmación de este caso alerta sobre su presencia a nivel regional. La leptospirosis equina ha sido reportada en Europa, EE.UU. y en algunos países de Sudamérica; y puntualmente existen áreas geográficas en donde la enfermedad parece representar un problema (Verna et al., 2013). En Argentina fue descripta en 1961 por Cedro y col. (Wegmann, 1983), pero la información respecto de su impacto en la producción ecuestre es escasa. Finalmente debemos recordar que la lepstospirosis es una zoonosis de gran importancia a nivel mundial (Stanchi et al., 2007). Reconocer su presencia y la dinámica de la enfermedad en las poblaciones animales permitirá tomar medidas para reducir su impacto en la salud pública.

\section{Bibliografía}

Adler B, De la Peña Moctezuma A. 2010. Leptospira and leptospirosis. Vet. Microbiol. 140: 287-296.

Brown PD, Carrington DG, Gravekamp C, van de Kemp H, Edwards CN, Jones SR, Prussia PR, Garriques S, Terpstra WJ, Levett PN. 2003. Direct detection of leptospiral material in human postmortem samples. Res. Microbiol. 8: 581-586.

Bryans JT. 1955. Studies on equine leptospirosis. Cornell Vet. 45: $16-50$

Carpio MM, IVersen JO. 1979. A serological survey of Leptospira interrogans serotype Pomona in Saskatchewan horses. Can. Vet. J. 20: 127-130.

D'Andrea A, Zamora Martinez Y, Alduina R, Monteverde V, Fernandez Molina C, Vitale M. 2012. Comparison of two PCR methods for detection of Leptospira interrogans in formalin-fixed and paraffin-embedded tissues. Mem. Inst. Oswaldo Cruz 107: 85-88.

Donahue JM, Smith BJ, Redmon KJ, Donahue JK. 1991. Diagnosis and prevalence of leptospira infection in aborted and stillborn horses. J. Vet. Diagn. Invest. 3: 148-151.

Edwards CN, Levett PN. 2004. Prevention and treatment of leptospirosis. Expert Review Anti Infective Therapy 2: 293-298.

Ellis WA, O'Brien JJ, Cassells JA, Montgomery J. 1983. Leptospiral infection in horses in Northern Ireland: serological and microbiological findings. Equine Vet. J. 15: 317-320.

Hodgin EC, Miller DA, Lozano F. 1989. Leptospira abortion in horses. J. Vet. Diagn. Invest. 1: 283-287.

Morter RL, Williams RD, Bolte H, Freeman MJ. 1969. Equine Leptospirosis. J. Am. Vet. Med. Ass. 155, 436-442

Pinna A, Martins G and Lilenbaum W. 2012. Leptospirosis and embryo recovery rate in mares. Vet. Rec. 170: 60. 
Poonacha KB, Donahue JM, Giles RC, Hong CB, PetritesMurphy MB, Smith BJ, Swerczek TW, Tramontin RR, Tuttle PA. 1993. Leptospirosis in Equine Fetuses, Stillborn Foals, and Placentas. Vet Pathol. 30: 362-389.

Slatter DH, Hawkins CD. 1982 Prevalence of leptospiral titres in normal horses. Aust Vet J. 59: 84-86.

Stanchi N, Brihuega B, Gatti E. 2007. Leptospirosis (pp. 320325). En: Stanchi N, Martino P, Gentilini G, Reinoso Echeverría M, Leardini N, Copes JA, Ed. Microbiología Veterinaria. Buenos Aires, Argentina, Intermédica.

Verma B, Biberstein EL, Meyer E. 1977. Serologic survey of leptospiral antibodies in horses in California. Am. J. Vet. Res. 38: 1443-1444.

Verma A, Stevenson B, Adler B. 2013. Leptospirosis in horses. Vet. Microbiol. 167: 61-66.

Wegmann E. 1983. Leptospirosis en caballos. Arch. Med. Vet. 15: 59-64.

Whitwell KE, Blunden AS, Miller J, Errington J. 2009. Two cases of equine pregnancy loss associated with Leptospira infection in England. Vet. Rec. 165: 377-378.

Wilkie IW, Prescott JF, Hazlett MJ, Maxie MG, van Dreumel AA. 1988. Giant cell hepatitis in four aborted foals: a possible leptospiral infection. Can. Vet. J. 29: 1003. 